Educational and Psychological Measurement

1991,51

\title{
A VALIDITY STUDY OF THE PAY SATISFACTION QUESTIONNAIRE (PSQ)
}

\author{
SHAWN M. CARRAHER \\ The University of Oklahoma
}

\begin{abstract}
The dimensionality of the Pay Satisfaction Questionnaire (PSQ) was examined using a principal components analysis with an oblique rotation and the parallel analysis criterion was used to determine the number of components to retain. It was found that the items which were supposed to load on the Raise scale instead loaded on the level and structure/administration components and that in fact a raise component did not exist. It was recommended that in the future researchers use more accurate methods to determine the number of components to retain and that they do not assume that the dimensions of compensation satisfaction are orthogonal.
\end{abstract}

IN a review of the pay satisfaction literature, Heneman (1985) argued that individuals develop a general attitude about their compensation as well as more specific attitudes toward each of several component parts of their compensation including (a) pay level (external competitiveness), (b) pay structure (internal consistency), (c) individual pay (employee contribution), and (d) with the administration of the entire pay system. Heneman and Schwab (1985) offered a multidimensional measure of the pay satisfaction construct. They hypothesized that compensation satisfaction included five dimensions: (a) satisfaction with pay level, (b) benefits, (c) raises, (d) structure, and (e) administration. A 20-item questionnaire called the Pay Satisfaction Questionnaire (PSQ) was developed and employed a 5-point Likert-type response format. This newly developed instrument was administered to three heterogeneous groups of white-collar employees. The first group consisted of 59 employees of a life insurance company. The second group included 90 evening

Copyright (C) 1991 Educational and Psychological Measurement, Inc. 
students enrolled in MBA courses at three universities. The third group consisted of 206 employees of a manufacturing and construction company. After some preliminary analyses indicated few differences among the characteristics of the three groups, they were combined into a single sample. Based upon the results of both exploratory principal components analyses and confirmatory factor analyses a number of changes were made in the original instrument which led to the creation of an 18-item instrument that was hypothesized to measure four dimensions: satisfaction with (a) pay level, (b) benefits, (c) raises, and (d) structure/administration. Confirmatory factor analysis and exploratory principal components analysis were then conducted on data obtained with the newly revised instrument for a sample of 1,980 nurses. The analysis revealed support for the four dimensional nature of the PSQ (Heneman and Schwab, 1985).

Since Heneman and Schwab (1985) called for more research on the PSQ, additional research has been done (Ash, Bretz, and Dreher, 1990; and Mulvey, Miceli, and Near, 1990 provide reviews of most of the studies that have been conducted). Noticeable in the research on the dimensionality of the PSQ is the lack of consistency in the reported number of factors within the PSQ. There is strong support for both three- and four-factor solutions with some support for as few as two or as many as five factors (Mulvey et al., 1990). After examining the existing studies on the dimensionality of the PSQ, Ash et al. (1990) concluded that compensation satisfaction consists of two independent dimensions identified as pay level (L) and benefits (B) with a third dimension labeled structure/administration which is not independent from pay level. Ash et al. (1990) further suggested that two of the four Raise (R) items (PSQ3, "my most recent raise" and PSQ7, "the raises I have typically received in the past") should be considered as part of the Level scale and that the other two (PSQ4, "influence my supervisor has on my pay" and PSQ16, "how my raises are determined") be considered as part of the Structure/Administration (S/A) scale.

\section{Purpose}

The purpose of this study was to explore the dimensionality suggestions offered by Ash et al. (1990) with a sample comparable to the one employed by Heneman and Schwab (1985) during the development of the PSQ. In this vein three questions are addressed: (a) should the raise items continue to be amalgamated into their own scale purported to measure satisfaction with raises, (b) is the 
dimension of structure/administration separate from that of pay level, and (c) how valid is the assumption of orthogonality between hypothesized dimensions of compensation satisfaction.

\section{Method}

\section{Instrument}

Pay Satisfaction Questionnaire. The PSQ is an untimed, 18-item instrument which purportedly measures compensation satisfaction in a multidimensional fashion. Responses to each of the PSQ items are in the form of a 5-point Likert-type response format with scale points labeled "very dissatisfied" (1), "dissatisfied" (2), "neither satisfied nor dissatisfied" (3), "satisfied" (4), and "very satisfied" (5). The PSQ takes approximately 3 to 5 minutes for an individual to complete.

\section{Subjects}

The sample was made up of 146 MBA students attending evening courses at one of three campuses of a Southeastern university. The subjects were all employed and reportedly worked an average of 44.19 hours per week $(S D=7.78)$. The average annual compensation was $\$ 33,016.67(S D=\$ 11,062.62)$.

\section{Analysis}

The PSQ data were analyzed using two separate principal component analyses (PCA). The first employed an orthogonal method of rotation (varimax) and the second used an oblique method (oblimin). A comparison of the hyperplane counts ( 4 for the varimax rotation and 31 for the oblimin rotation) led to the conclusion that an oblique method was more appropriate for this data. The method used to determine the number of components to retain was the parallel analysis criterion which Zwick and Velicer (1986) found to be the "most frequently accurate method" (pp. 440) examined. Cutoff loadings were considered significant at or above the .50 level.

\section{Results and Discussion}

The results of the PCA with an oblimin rotation are provided in Table 1 along with the coefficient alpha reliabilities for the three 
TABLE 1

Results of Principal Components Analysis

\begin{tabular}{|c|c|c|c|}
\hline PSQ item & F1 & $\mathrm{F} 2$ & F3 \\
\hline PSQ1 (L) My take home pay & .920 & .038 & -.061 \\
\hline PSQ5 (L) My current salary & .936 & -.035 & .024 \\
\hline PSQ10 (L) My overall level of pay & .929 & .042 & -.026 \\
\hline PSQ14 (L) Size of my current salary & .951 & -.025 & -.018 \\
\hline PSQ2 (B) My benefit package & .009 & .944 & .033 \\
\hline PSQ6 (B) Amount the company pays toward my benefits & .066 & .889 & -.006 \\
\hline PSQ11 (B) The value of my benefits & -.005 & .943 & .033 \\
\hline PSQ15 (B) The number of benefits I receive & .020 & .957 & -.010 \\
\hline PSQ3 (R) My most recent raise & .622 & .108 & .055 \\
\hline PSQ4 (R) Influence my supervisor has on my pay & -.027 & -.054 & .641 \\
\hline PSQ7 (R) The raises I have typically received in the past & .665 & .098 & .074 \\
\hline PSQ16 (R) How my raises are determined & .327 & -.088 & .626 \\
\hline PSQ8 (S/A) The company's pay structure & .443 & -.094 & .515 \\
\hline $\begin{array}{l}\text { PSQ9 (S/A) Information the company gives about pay } \\
\text { issues of concern to me }\end{array}$ & .238 & -.026 & .552 \\
\hline PSQ12 (S/A) Pay of other jobs in the company & .065 & .120 & .670 \\
\hline PSQ13 (S/A) Consistency of the company's pay policies & -.099 & .046 & .845 \\
\hline PSQ17 (S/A) Differences in pay among jobs in the company & -.039 & .052 & .829 \\
\hline PSQ18 (S/A) How the company administers pay & -.061 & .068 & .833 \\
\hline Eigenvalues & 8.58 & 2.65 & 1.63 \\
\hline Reliabilities & .9272 & .9608 & .8895 \\
\hline
\end{tabular}

components retained. The parallel analysis criterion was in agreement with Kaiser's Rule as to the number of components to keep.

As can be seen in Table 1, three components were retained and the Raise items loaded as Ash et al. (1990) had proposed. Both PSQ3 and PSQ7 loaded on the Level scale and both PSQ4 and PSQ16 loaded on the S/A scale as hypothesized. However, with a loading of .33 on the Level component PSQ16 may not be considered as falling in the hyperplane. Three of the five non-primary loadings which are not in the hyperplane emerged with S/A items (PSQ8, PSQ9, and PSQ16) on the Level component. Thus, this observation adds support to the notion that the S/A scale is not totally independent of the Level scale. Also, obtained reliability estimates of .9272 (Level), .96 (Benefit), and $.89(\mathrm{~S} / \mathrm{A})$; led to the conclusion that the scales composing the three components have an acceptable level of reliability.

This study supports the arguments of Ash et al. (1990) concerning both the loading of the Raise items on other scales and the non-independence of the S/A scale. Also as it was found that the oblique solution was more nearly appropriate than the orthogonal one, future researchers should seriously consider the perspective of Mulvey et al. (1990) who advised that the assumption of orthogo- 
nality between hypothesized dimensions of compensation satisfaction, regardless of the nature of the individual dimensions, is suspect. Finally, it would be useful for future researchers to use more accurate methods than Kaiser's Rule to determine the number of components to retain. In this study, although Kaiser's Rule was in agreement with the parallel analysis criterion, Zwick and Velicer (1986) have cautioned its usage.

\section{REFERENCES}

Ash, R. A., Bretz, R. D., and Dreher, G. F. (1990). The measurement and dimensionality of compensation satisfaction in law enforcement. Paper presented at the fifth annual conference of the Society for Industrial and Organizational Psychology, Miami Beach.

Heneman, H. G. (1985). Pay satisfaction. Research in Personnel and Human Resources Management, 3, 115-139.

Heneman, H. G. and Schwab, D. P. (1985). Pay satisfaction: Its multidimensional nature and measurement. International Journal of Psychology, 20 (2), 129-141.

Mulvey, P. W., Miceli, M. P., and Near, J. P. (1990, May). The Pay Satisfaction Questionnaire: A confirmatory factor analysis. Ohio State University working paper. Columbus: Ohio State University.

Zwick, W. R. and Velicer, W. F. (1986). Comparison of five rules for determining the number of components to retain. Psychological Bulletin, 99, 432-442. 